THE INTERNATIONAL

REVIEW OF RESEARCH IN

OPEN AND DISTANCE LEARNING

\title{
Rapport in Distance Education
}
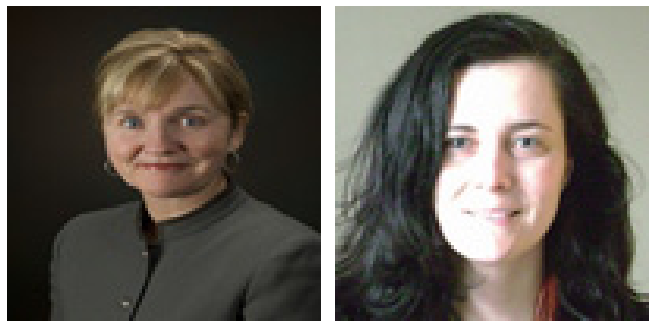

Elizabeth Murphy and María A. Rodríguez-Manzanares Memorial University, Canada

\section{Abstract}

Rapport has been recognized as important in learning in general but little is known about its importance in distance education (DE). The study we report on in this paper provides insights into the importance of rapport in $\mathrm{DE}$ as well as challenges to and indicators of rapport-building in DE. The study relied on interviews with 42 Canadian high-school DE teachers. Findings revealed that rapport is necessary in DE because of the absence of faceto-face communication. Challenges to building rapport relate to the geographic dispersion of students, the asynchronous nature of DE, teacher workload, limits of the software, teachers and students not seeing the need for rapport, and DE traditions. We identified six categories of rapport-building in DE as follows: Recognizing the person/individual; Supporting and monitoring; Availability, accessibility, and responsiveness; Non text-based interactions; Tone of interactions; Non-academic conversation/interactions. We break the categories into subcategories and provide indicators for each one. The indicators might also be used in contexts of DE teacher professional development as a springboard for discussion, or, more prescriptively, as guides to DE teacher behaviour. A follow-up study using a more fine-grained focus on specific indicators might provide insights into specific rapport-related behaviours.

Keywords: Distance education; online learning; rapport; teachers' beliefs; high school education

\section{Rapport in Distance Education}

Benson, Cohen, and Buskist (2005) found that in classes where teachers established rapport students were more likely to attend class, pay attention, and enjoy the subject matter. Frisby and Martin (2010) found that instructor rapport emerged as a significant predictor of cognitive and affective learning. Granitz, Koernig, and Harich (2009) linked rapport with 
enhanced learning, attention, motivation, attendance, and involvement for students. For faculty, they linked rapport with more rewarding teaching and higher ratings/evaluations. Not surprisingly, given these outcomes, the authors concluded that "one of the key traits of a master teacher is the ability to foster student rapport” (p. 52).

Rapport, defined as harmonious interactions between teachers and students (Bernieri, 1998) or a relationship with mutual understanding and satisfactory communication (Carey, Hamilton, \& Shanklin, 1986), is identified as important in the literature. However, that literature is primarily concerned with learning in face-to-face contexts. What about rapport in a context of distance education (DE)? Is rapport-building important or even possible in DE? In a Canadian study of high-school DE, Murphy and Rodríguez-Manzanares (2008a) found that the absence of "body language and visual presence as mediators requires eteachers [DE teachers] to find new ways of interacting and building rapport” (p. 1061). The authors contrasted the spontaneous, informal, daily interactions in the physical classroom with the situation in the DE classroom. In the former setting, teachers can easily build rapport. In the latter, the authors argued, "rapport building must be premeditated, consciously promoted and can only be achieved with more work" (p. 1068).

In spite of its importance and compared to other classroom variables, little is known about rapport. Studies conducted on the construct have not necessarily focused on educational contexts (e.g., Gremler \& Gwinner, 2000; Macintosh, 2009a, 2009b). Not surprisingly, it remains, therefore, a "relatively new variable to be considered in the educational setting" (Frisby \& Martin, 2010, p.160). In a context of DE, even less is known about the construct, its importance, how it might be built, and what it might look like. The psychology literature includes some attempts to identify indicators or evidence of rapport; however, these attempts have all been in contexts of face-to-face interactions (e.g., Bernieri, Gillis, Davis, \& Grahe, 1996; Miles, Nind, \& Macrae, 2009). In this paper, we report on a study that probed teachers' beliefs about rapport in a context of DE. Specifically, we report on its importance, challenges to rapport-building, and indicators of rapport in DE. We begin by examining how rapport has been conceptualized in the literature.

\section{Rapport in the Literature}

Rapport is a dyadic phenomenon (Altman, 1990), experienced only in interaction between individuals, and not a personality trait (Tickle-Degnen \& Rosenthal, 1990). It is therefore a mutual phenomenon characterized by mutual attentiveness (Tickle-Dengen \& Rosenthal, 1990), mutual respect (Kyriacou, 2009), mutual openness (Granitz et al., 2009), mutual attention (Hall, Roter, Blanch, \& Frankel, 2009), and mutual understanding (Carey et al., 1988). The mutual attention, however, must be positive or harmonious in nature.

Tickle-Dengen and Rosenthal (1990) argue that rapport would not be present when the attentiveness is negative. Therefore, rapport involves harmonious understanding (Kyriacou, 2009), harmonious interactions (Bernieri, 1998), and harmonious relations (Gremler \& Gwinner, 2000; Spencer-Oatey, 2000). It involves being “on the same wave length" (Berni- 
eri, 1988) or clicking (Tickle-Dengen \& Rosenthal, 1990).

Coordination is another element in rapport. According to Tickle-Dengen and Rosenthal (1990), coordination refers to balance and regularity in the mutual attentiveness; however, the coordinated movements of individuals on a crosswalk do not imply rapport. "Smooth and efficient interactional coordination" (p. 288) occurs when individuals know one another and are able to adopt one another's perspective. In a study of rapport between medical students and patients, Hall et al. (2009) defined rapport as "a relationship that was pleasant and engaging, a high degree of liking or positive affect, mutual attention, harmonious relation, easy/smooth communication, and/or symmetry and synchrony in the interaction" (p. 324).

Figure 1 presents the elements of rapport as articulated in our summary of the literature.

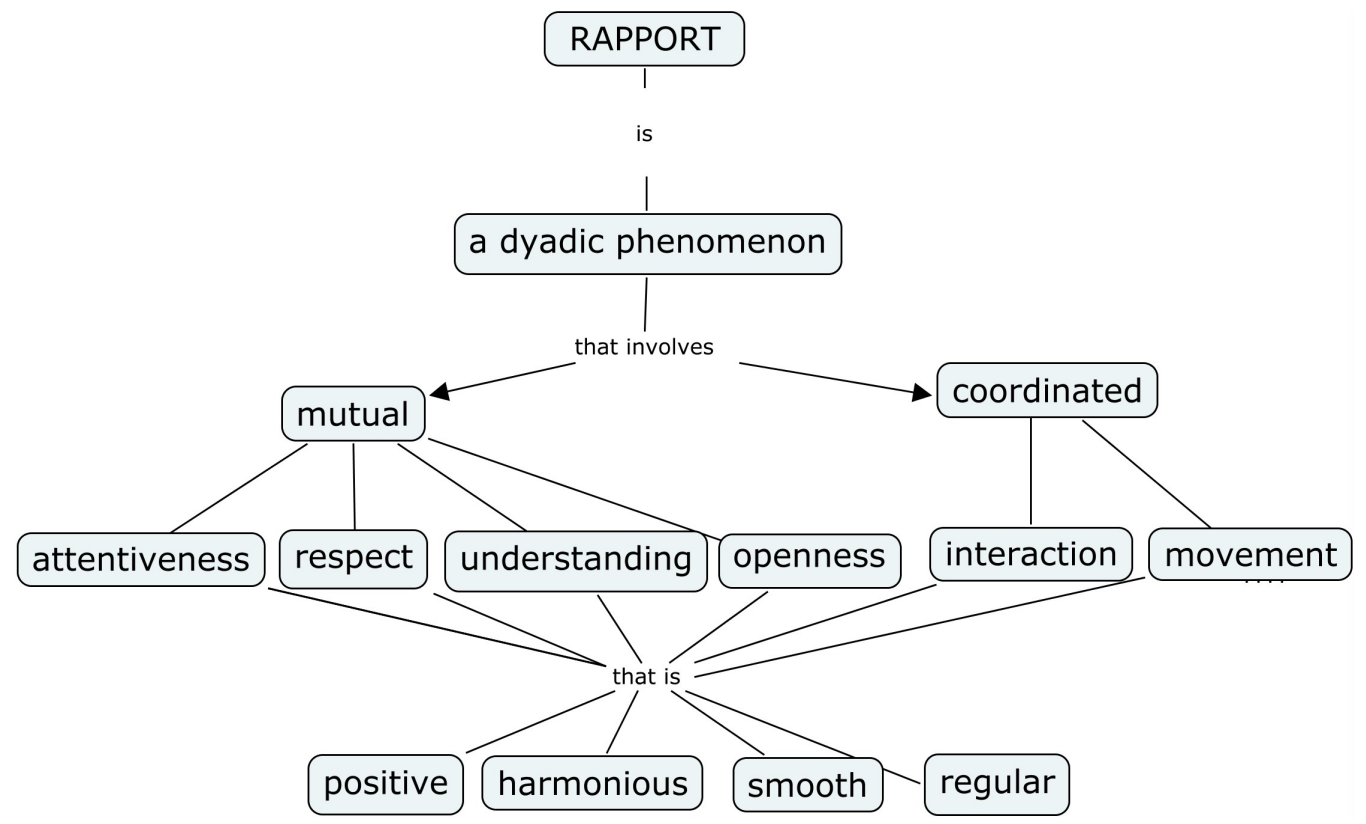

Figure 1. The elements of rapport.

\section{Indicators of Rapport}

The next step after defining rapport and identifying its elements is to identify how it might manifest itself or be operationalized in terms of behaviours such as coordinated movements or interactional synchrony (Bernieri, 1988), matched body language (Marks, 1994), matched voice tone and gestures (Nickels, Everett, \& Klein, 1983), behavioural and posture sharing, mimicry or mirroring (Gillis, Bernieri, \& Wooten, 1995; Granitz et al., 2009; Lakin \& Chartrand, 2003; Shapiro, 1989). Tickle-Dengen and Rosenthal (1990) paid particular attention to nonverbal behaviour as a key element in creating rapport. They referred to spatial configurations and "bodily postures" as attentiveness correlates of rapport and behaviours such as smiling and head nodding as positivity correlates, while the coordination correlates would be behaviours such as "postural mirroring and interactional synchrony" (p. 290). 
Kyriacou (2009) discussed rapport from the perspective of classroom effectiveness, arguing that effective classrooms are task-oriented but are also characterized by "mutual respect and rapport" (p. 115). Rapport involves care for the students' progress and mutual respect for students as learners and as individuals. Indicators of mutual respect include tailoring learning to students' needs; monitoring progress and giving help patiently and constructively; giving praise; and "dealing with lack of progress in a concerned manner" (p. 116). Respect through treating students as individuals (independent of school) contributes to good rapport. Social conversation and remarks such as "Anyone go to the match on Saturday?" (p. 117) are also indicators of rapport.

Granitz et al. (2009) identified three categories of what they referred to as "antecedents of rapport." These are: approach, personality, and homophily. The category of approach includes being available to answer questions; providing guidance, feedback, support, help and praise for good work; accessibility, responsiveness, and openness (e.g., providing a home telephone number). It includes mutual openness and disclosure, understanding the student as a person, and recognizing differences between teachers and students. The category of approach also involves creation of trust through fulfillment of contracts and promises and through consistent and predictable behaviours; respect and courtesy; not psychologically threatening students by talking down to them; listening; paying attention; showing patience; and taking time with students. This latter element of rapport also includes showing interest in student success and helping and encouraging them to succeed. In addition, it involves being honest and transparent, showing students one's human side, admitting faults and mistakes, exerting an effort, and expecting effort from students.

Personality factors related to rapport include caring, bonding, showing concern and empathy, and avoiding favouritism. Rapport includes creating a positive, friendly, cooperative environment, using humour, and understanding students' needs. Homophily relates to sharing values, attitudes, social style, beliefs, and behavioural mimicry. It involves engaging in self-disclosure and posture sharing or similarity in movement (Granitz et al., 2009).

\section{Indicators of Rapport in Distance Education}

The previous section identified indicators of rapport in general and in education in particular. This section focuses specifically on identifying indicators of rapport in a context of DE. There has been limited attention in the literature thus far pertaining to the types of behaviours that might be indicative of rapport in that context. Stock (2010) considered rapport in a context of staff-patron interactions in a reference library. He noted that in an online context because of the absence of voice and nonverbal behaviour, paying attention to factors such as "the length of the patron's sentence and level of formality and writing a response in approximately the same style" can help build rapport (pp. 48-49). He also argued that in cases where the phone is used voice plays an important role in building rapport especially when aspects such as tempo and volume are matched.

Jones, Warren, and Robertson (2009) studied rapport in a context of online text-based communication in a $3 \mathrm{D}$ online learning environment (OLE). Rapport elements in messages were indicated by the following: reporting on or requesting information on personal infor- 
mation, ideas, opinions, and emotions. Thanking, complaining, apologizing, or engaging in personal discussions were also considered as indicators of rapport. The authors concluded that the earlier weeks in a course represent a critical period for the type of student interaction that will lead to rapport. In particular, face-to face meetings early in the course help develop a critical communication mass that positively supports the development of rapport. The visual nature of a 3 D OLE (with hand gestures, facial expressions) supports more naturalistic communication similar to that of face-to-face interactions.

In a study of 15 high-school DE teachers, Murphy and Rodríguez-Manzanares (2008a, $2008 \mathrm{~b}$ ) found that because of a lack of visual cues and physical presence in this form of learning teachers compensated by deliberate rapport-building. Teachers described their compensatory strategies such as having students' photographs and keeping track of information related to their preferences and extracurricular activities. Other strategies included providing constant and immediate feedback, sharing personal information, engaging in non-course related, off-task chat, getting to know students socially, ensuring that communication is comfortable, making personal contacts, and using technologies such as instant messaging with which students are comfortable.

\section{Summary of Rapport Indicators}

In Table 1, we synthesize and categorize the indicators of rapport as articulated in the literature in general and in the DE literature specifically. We have grouped like indicators and provided labels in italics. 
Table 1

Summary of Rapport Indicators in the Literature

Disclosure, honesty and respect

Being open, honest, and transparent

Showing students one's human side

Admitting faults and mistakes

Talking freely

Engaging in self-disclosure

Thanking, apologizing

Sharing personal information

Creating trust through fulfillment of contracts and promises

Not psychologically threatening students by talking down to them

Showing consistent and predictable behaviours
Supporting and monitoring

Showing care for and monitoring students progress

Tailoring learning to students' needs

Providing guidance, feedback, support, help

Giving praise for good work

Giving help patiently and constructively

Dealing with lack of progress in a concerned manner

Showing patience with students

Exerting and expecting effort from students

Listening and paying attention

Showing interest in student success

Helping and encouraging them to succeed

Creating a positive, friendly, cooperative environment

\section{Recognizing the person/individual}

Understanding the student as a person

Recognizing differences

Avoiding favouritism

Reporting on or requesting personal information, ideas, opinions, and emotions

Engaging in personal discussions

Keeping track of students' photos and information related to their preferences and extra-curricular activities

Making personal contacts
Sharing, mirroring, mimicking, matching

Being "on the same wave length"

Adopting each other's perspective

Behavioural and postural sharing, mirroring, and mimicry

Writing a response in the same style

Matching body language, gestures, voice tempo, and volume

Smiling and head nodding

Sharing values, attitudes, social style, beliefs 
Interacting socially

Engaging in social conversation

Engaging in non-course related, off-task chat

Getting to know students socially

Using humour
Availability, accessibility, and responsiveness

Being available to answer questions

Being accessible

Being responsive

Providing constant and immediate feedback
Caring and bonding

Being caring

Bonding

Showing concern

Showing empathy and an understanding of students' needs

\section{Communicating effectively}

Ensuring that communication is comfortable, easy/smooth

Using technologies such as instant messaging with which students are comfortable

\section{Method}

The previous section of this paper focused on indicators of rapport in the literature. The limited attention in the literature to indicators of rapport specifically for DE provided the motivation for this study. In addition, our purpose was to identify why rapport was important in $\mathrm{DE}$ and what challenges might be associated with rapport-building in DE. To achieve these three objectives, we interviewed 42 Canadian high-school teachers. It was beyond the scope of the study to observe rapport in DE (i.e., to identify how these 42 teachers actually engage in rapport-building in their courses). Our focus was on teachers' beliefs or personal theories (Fox, 1983; Siedentop, 1991) related to rapport in DE.

\section{Recruitment of Participants and Ethics Procedures}

The first step in recruitment of participants involved identifying organizations delivering DE high-school courses in Canada. Different models of the provision of high-school DE exist in different regions. For this reason, we identified a variety of organizations such as school districts and virtual schools. For each organization, we identified a contact person or persons in order to request permission to recruit teachers for the study. These organizations included, for example, virtual school principals as well as individuals working for provincial departments of education or school districts. For the organizations that replied to our call for participation, we then proceeded to contact individual teachers by sending them a consent form and a letter inviting them to participate in the study. 


\section{Participants}

Forty-two DE teachers who returned consent forms were included in the study. They worked in 14 organizations located in the provinces of British Columbia, Alberta, Saskatchewan, Manitoba, Ontario, Quebec, New Brunswick, and Nova Scotia. The number of teachers affiliated with any one of the 14 organizations ranged from one to six. All the teachers worked for a single organization, except for one who taught for two organizations. While 19 teachers reported to a principal either in their online school or in the school where they taught their face-to-face classes, one teacher reported to the principals of the schools in which the students were registered for face-to-face classes. One teacher was working both as a principal and a teacher. The remaining 21 teachers reported directly to a coordinator of DE for an area greater than a single school. For seven of these teachers, the coordinator worked for the school board, while six reported to an individual employed by the provincial Department or Ministry of Education. Eight teachers stated that they reported to one or more individuals employed by different institutions at a variety of levels.

\section{Data Collection}

We conducted individual one-hour, audio-taped telephone interviews over a two-month period. Interviews were semistructured (Patton, 2002). The advantage of semistructured interviews is that they allow the researcher "to respond to the situation at hand, to the emerging worldview of the respondent, and to new ideas on the topic" (Merriam, 2009, p. 90). We used probing to gain further insight into participants' beliefs about rapport in their DE courses. As King and Horrocks (2010) observed, stronger probing may be needed in telephone than in face-to-face interviews. In the absence of visual cues, probing allows the researcher to resolve ambiguities in communication in qualitative telephone interview studies. In addition, probing can be useful when conducting telephone interviews because participants might need to be "encourage[d] to open up if their responses are becoming too 'factual' in tone" (p. 83).

We asked three questions to the teachers:

1. Is building rapport important in DE?

2. What are the challenges related to promoting rapport in DE?

3. In what ways do you build rapport between yourself and students in DE?

\section{Data Analysis}

We began by transcribing the interviews. We then gathered the interview segments on rapport and unitized them (Miles \& Huberman, 1994) by breaking the text of the transcripts down into units of meaning, containing one identifiable idea (Aviv, 2001). Rather than looking, for example, at "a word, a sentence, or a section" (Marshall, 1981, p. 396), the focus was on searching for logical units or "chunks of meaning" (p. 396) coming out of the data. We labelled each segment of text that formed a unit of meaning. Analysis proceeded 
by identifying thematically similar units across the data (Lee \& Fielding, 2004). The regularities identified revealed patterns that we sorted into categories (Patton, 2002).

\section{Findings}

We present the findings in three sets. The first set consists of responses to the first question, which asked teachers if it was important to build rapport in DE. The second set groups responses to the question about challenges related to building rapport in DE. The third set of findings related to rapport-building between teachers and students. Based on our analysis of the interview transcripts, we grouped approaches to rapport-building into six categories. We broke the categories into subcategories and provided indicators for each.

\section{The Importance of Rapport in Distance Education}

Teachers emphasized that rapport is necessary because in DE there isn't face-to-face communication. It is important to "establish some sort of personal connection;" otherwise, it is like teaching "a bunch of little computers." Getting to know students individually is important and that includes knowing "how they think, how they work, what their personalities are, what they can handle, what they can't handle.”

Having an idea of a given student's situation is important because, for example, "a student might be... a single parent, who has a young child, and that gives us a better understanding of why they are delaying in providing some answers." Another might have a parent who is terminally ill. The student could have an emotional disorder. Rapport is required "because we [teachers] have to treat each individual student in a different manner." As well, "the more contact that you have with the student and the more familiar you are with them, the more they contact you regularly, the greater the chance of their success."

\section{Challenges to Rapport-Building in Distance Education}

Some teachers noted that building rapport with DE students can be more challenging, especially when students are scattered across the province or when they are not together at the same time, or working on their assignments outside of office hours. As one teacher commented: "I can't say that I've really... established a rapport among students."

Rapport can be difficult to establish, not only because of the distances created by geography, but also because of the way the courses are designed and the limits of the software: "For example, Moodle doesn't have a built-in synchronous tool. It's essentially an asynchronous tool." The workload may also present obstacles to a teacher's engagement in rapport, as the following remark illustrates: “... we have some students who could keep you on the phone for an hour at a time, but, unfortunately you have to attend to more than one student, so... I try to limit [discussion] to academic questions." In other cases, teachers may not see the need for or value of rapport: "Building rapport in a social sense is not something that's happening right now, nor would I say it is something that is really essential to having the students benefit in an educational sense from the course." 
Compared to the face-to-face student who is "there partly by obligation," the DE student is there by his or her "own free will." As a result, some DE students "don't want to have any interactions. They're just getting through it because they have to get through it." Some DE students may not want to be contacted. "They just want to get in, get this course done, and get out." One teacher described his own challenges with trying to build rapport:

There are literally children that [sic] send in emails with just attachments; they don't give any email responses, they don't write comments, they don't write questions. And I send back to them things like: received and read, great job, great work, and I make comments... and I receive no response. I have no sense of them as people.... it's their decision to decide whether they want to contribute to the other side of this kind of banter... if they don't, that's fine. I would feel really awkward sending an email to a kid who was being very business-like saying "Hey, let's chat! How do you feel?”

Another teacher cautioned about how in an online environment, attempts to build rapport might backfire:

...you have to be very careful what you say: you might be trying to make a joke with a student, but if you don't know their sense of humour, they don't see it as a joke ... because you don't know what kind of day they're having or what kind of situation they're in.

Other obstacles to rapport-building relate to traditions of DE. In the following comment, one of the participants explained how past practices with $\mathrm{DE}$ in his province may inhibit attempts to build rapport:

...the people who took distance education in the olden days did so without any contact with the teacher. They received their lessons in the mail, and they completed them, and they mailed them back... there was no chatter at all with the teacher. And so that perception is still out there, and some students who take online courses believe that they're not supposed to contact the teacher, even though we... keep telling them, 'Now, please, phone whenever you have a question or need assistance or anything like that.'

In spite of these challenges related to rapport-building in DE, teachers nonetheless identified numerous indicators of rapport-building in this context. These are described in the next section. 


\section{Indicators of Rapport in Distance Education}

Our analysis of the transcript of interviews with the 42 teachers revealed six categories of rapport-building as follows: Recognizing the person/individual; Supporting and monitoring; Availability, accessibility, and responsiveness; Non text-based interactions; Tone of interactions; Non-academic conversation/interactions. We broke the categories into subcategories and provided indicators for each. The indicators use as much as possible the actual words of interviewees. We summarized the categories and subcategories in Table 2.

Table 2

Summary of Categories and Subcategories

\begin{tabular}{ll}
\hline Categories & Subcategories \\
\hline Recognizing the person/individual & Eliciting personal information \\
& Expressing personality \\
& Acknowledging the person \\
\hline Supporting and monitoring & Supporting and monitoring \\
& Praising \\
& Providing feedback
\end{tabular}

Availability, accessibility, and responsiveness $\quad$ Being available

Responding quickly

Non text-based interactions

Hearing each other

Seeing each other

Interacting in real-time, face-to-face

Tone of interactions

Being friendly

Being humorous

Being respectful and honest

Non-academic conversation/interactions

Conversing socially 
The indicators of rapport included in the category of Recognizing the person/individual focus on the individual or person, beyond the academic setting. The indicators relate to eliciting and acknowledging aspects of students' personality, interests, hobbies, pastimes, and future plans. They also include teachers' disclosure of personal information. We summarize the subcategories and their indicators in Table 3.

Table 3

Category: Recognizing the Person/Individual

Subcategory Indicator

Eliciting personal information
Setting up profiles or homepages at the beginning of the course where students post pictures of themselves and answers to questions related to personal interests, such as the type of music they like.

Using chat to learn the attitudes, temperaments, and likes and dislikes of students.

Encouraging students to write about their personal interests.

Finding out at the beginning of the year students' interests and likes, then asking questions about them later, e.g., "Hey, how did your volleyball game go?"

At the very beginning of the course, using a 10-question assignment that elicits information from the student.

Finding out some personal information early on so that you can build on that as you go through the course.

Getting students to tell a little bit about themselves, what brought them to online learning, what their interests, hobbies and pastimes are, and what they plan to do after graduation, etc.

Having students use a course café to introduce themselves and their interests, and why they are taking the given course.

Getting to know who students are, chatting about what their future ambitions are, and what they are planning on doing after graduation. 

Expressing person- Having students choose the colours and the fonts to represent their personali- ality ties.

Letting the teacher's personality come through as much as possible.

Having students and teachers post discussion messages about themselves.

Having teachers create their own profile page.

Teachers disclosing certain amounts of personal information about themselves, such as interests and hobbies, so that students feel like they know them a little bit.

Personalizing the welcome pages to the courses.

Acknowledging the Noticing personal things about students.

person

Engaging students at a personal level outside the course.

Using chat to establish some sort of relationship outside of the academic setting and getting to know a bit more about students personally.

Sending personalized emails and comments specific to a student in order to acknowledge the person.

Making connections, so that each time students contact the teacher, the teacher can look them up in the file and say, "Oh, yeah, this is that student," so they are able to continue the relationship.

Unlike the previous category, which focuses on personal attention, the category Supporting and monitoring relates more specifically to the academic aspects of the teacher's interactions with students. The category groups indicators that refer to the teacher's efforts to ensure that students remain on track and on task. The category also includes attention to the affective component of learning in terms of reducing or preventing students' frustration or discouragement. We summarize this category in Table 4. 
Table 4

Category: Supporting and Monitoring

Subcategory Indicator

Supporting and monitoring
Posting emails that say, "If you're having trouble, come and talk to me."

Sending students a hard copy letter to welcome them to the course.

Sending emails to students regarding information so they know that the teacher is there trying to help them get through.

Asking students to submit a document explaining any special circumstances that the virtual school should be aware of.

Trying to read messages as if they were spoken, and then writing, phoning, or chatting with students to know that they are surviving and are not getting too frustrated.

Sending weekly emails to students just to make sure they are on track and are not discouraged with the course.

Sending information to schools and ccing the students, so they can see that the teacher is really looking out for them and making sure they are on task and getting work done.

Offering help to improve submissions.

Being willing to give students as much help as they need.

Praising 
Providing feedback Providing regular feedback from the teacher everyday in terms of how well students are meeting the outcomes of the lesson.

Returning a lesson with comments.

Not marking an assignment if a student had a problem on it, but returning it and saying, "You really had trouble with that assignment. How about you meet me on chat and we'll talk about it and you can re-submit it?"

Emailing students to provide positive reinforcement, encouragement, or feedback or to invite questions.

The category Availability, accessibility, and responsiveness in Table 5 groups indicators that reference the ongoing, easy, and immediate accessibility of the teacher to answer questions, welcome students, or address needs.

Table 5

Category: Availability, Accessibility, and Responsiveness

Subcategory Indicator

Being available Talking on a daily basis.

Having constant messaging going on.

Being accessible, offering chats and office hours, and making kids know that they can email you at any time.

Building the feeling that students are welcome to email at any time.

Being available to provide help to students.

Making it as easy as possible for students to get in contact and stay in contact.

Being there to answer students' questions.

Responding quickly Responding as soon as possible when students ask a question or want something.

Addressing students' needs in a timely fashion. 
Table 6 groups the indicators for the category Non text-based interactions. This category references the tools used by teachers to contact students. In particular, it emphasizes realtime interactions such as those provided through phone and video. This category also includes interactions that occur in person such as in face-to-face visits by teachers.

Table 6

Category: Non Text-based Interactions

Subcategory Indicator

Hearing each other Letting students hear your voice.

Making initial telephone calls to touch base and help develop a relationship.

Phoning new students.

Phoning the student and introducing oneself.

Calling students and talking.

Using phone contact first because, in the voice, we hear friendliness and antagonism.

Seeing each other Using webcams to see each other.

Providing an opportunity for students to see a picture of you, to hear your voice on video.

Having weekly meetings using real-time, web conferencing to see others' expressions. 
Interacting in real- Inviting students to come to specific sessions such as a provincial exam prepatime, face-to-face ration session.

Holding a ski trip.

Holding a picnic.

Holding an open house in the virtual school and inviting other students to come, and having games and pizza for them.

Going out to the schools and meeting the students.

Table 7 presents the indicators related to the category Tone of interactions. This category suggests that rapport, at least in part, is a function of the tone of the communication. The tone might communicate humour and respect and it may be light, honest, friendly, and warm.

Table 7

Category: Tone of Interactions

\begin{tabular}{ll}
\hline Subcategory $\quad$ Indicator \\
\hline
\end{tabular}

Being friendly Exchanging pleasantries.

Being as positive as possible.

Teacher revealing to students that he or she is pretty easy-going.

Having a more jovial relationship.

Building a relationship with that student, so it doesn't feel as cold.

Addressing students' needs in a friendly fashion.

Being approachable and friendly. 
Being humorous

Teachers revealing to students their sense of humour.

Joking with the students as much as possible.

Having a sense of humour.

Being respectful and honest
Treating students with respect and showing that they are important to you.

Respecting the commitment that students are making.

Showing students respect in the chat room.

Conveying to students respect for making such a big commitment.

Treating students like adults.

Admitting mistakes.

Table 8 groups indicators related to the category of Non-academic conversation/interactions between students and teachers. This category highlights the social nature of rapport and emphasizes the affective components of caring and empathy. Unlike the category presented in Table 4 (Supporting and monitoring), it emphasizes monitoring and supporting students personally, as opposed to solely academically.

Table 8

Category: Non-academic Conversation/Interactions

Subcategory Indicator

Conversing socially Initiating small talk.

Communicating with students on a social level.

Seeking ways to have conversations with students.

Talking about off-topic issues.

Part of the teacher's message should not be business-related, but should be, "Hope you're having a good week. Grad's coming up: did you get your dress?"

Sending students emails that would be more in the sense of banter. 
Showing care and concern
Answering students when they ask questions and asking them about other things, like "Are you having a good week this week?"

Asking "How was your weekend? How are you feeling today?"

If students have had a personal problem, checking up with them later on to make sure that everything is ok.

Text messaging students to ask them how their day is going.

Saying good morning to them, and asking them how their day is going.

Talking to students about things that are important in their life.

Asking students how they are doing.

Showing care, that you are on the student's side, and that the student is not just another number.

Not downplaying students' feelings.

\section{Discussion}

In addition to identifying indicators of rapport, the previous section identified the importance of rapport as well as challenges associated with rapport-building in DE. Teachers presented two different types of beliefs or personal theories concerning rapport. One emphasized its importance given the online context as a mechanism that compensates for the anonymity resulting from lack of face-to-face interactions. The other downplayed its importance and highlighted limitations related not only to time, software, and traditions of $\mathrm{DE}$, but to preferences on the part of students.

Teachers' beliefs about the importance of rapport may have been limited by our first question, which simply asked whether rapport was important in DE. If we had provided teachers with a list of indicators of rapport from the literature and asked them to identify which were important, all the teachers might have selected some of the indicators. This is because a number of the indicators, although associated with rapport in this context, are indicative simply of effective teaching in general. These indicators might relate to giving praise (Kyriacou, 2009), showing respect for students (Delaney, Johnson, Johnson, \& Treslan, 2010; Granitz et al., 2009), creating a positive atmosphere (Granitz et al., 2009), using humour, providing timely feedback, or being accessible and communicative (Delaney et al., 2010).

Rapport, as noted already, has been described as a dyadic phenomenon experienced only in 
interaction between individuals. Tickle-Degnen and Rosenthal (1990) emphasized the notion of mutual coordination as an element in rapport such as adopting the other's perspective or posture sharing and mimicry. We identified three indicators of rapport which reflect this mutual interaction and which we grouped in the category Recognizing the person/ individual. However, our findings focus more on teachers' role in rapport-building and, in that regard, the dyadic, mutual character of the construct is downplayed in favour of teachers' conscious efforts to engage in rapport behaviours directed toward the student. Those efforts do not reference any expectations of or requirements for the student to reciprocate. For example, one teacher described promoting rapport by asking students about their personal interests. Another focused on letting the teacher's personality come through as much as possible.

The literature on rapport has come largely from contexts of psychology (e.g., Bernieri et al., 1996; Tickle-Degnen \& Rosenthal, 1990), the medical and counselling field (e.g., Barnett, 2001; Gaglio, Nelson, \& King, 2006; Hall et al., 2009), and marketing (e.g., DeWitt \& Brady, 2003; DeWitt \& Liu, 2002; Gremler \& Gwinner, 2000; Macintosh, 2009a, 2009b). It is possible that, in those contexts, rapport might be defined more as a mutual phenomenon. In a context of DE however, it may be that rapport-building is a task of the teacher. Teachers linked respect with rapport and referred to the importance of showing students respect for their commitment and treating them like adults. Kyriacou (2009) and Granitz et al. (2009) also identified respect as an indicator of rapport, although they described it as a mutual phenomenon. Also, the question we asked teachers about rapport-building did not focus on its mutual dyadic nature.

The nonverbal behaviours associated with rapport in the literature such as smiling and head-nodding or postural mimicry might be possible in a context of DE where video or webcams are used. As noted in the study by Stock (2010), mimicry can even be achieved in a text-based context through behaviours as mirroring sentence length. In our study, teachers did not refer to any types of mirroring. They did, however, refer to adapting or tailoring their behaviours to the students such as finding out their interests and then asking questions about them later. We may assume, therefore, that text-based mirroring and mimicry is an appropriate rapport-building behaviour in DE.

In terms of comparisons with the literature on rapport, teachers referenced many of the indicators that we identified in the literature. One notable exception would be those indicators grouped in the category Recognizing the person/individual as well as the indicator Avoiding favouritism. In a DE environment where interactions may be more one on one, favouritism may not be an issue. Teachers did not refer specifically to thanking students or apologizing to them, except for the one indicator that referred to admitting mistakes. Other indicators identified in the literature but not referenced by teachers include: Showing consistent and predictable behaviours and Creating trust through fulfilment of contracts and promises. Although teachers did not refer to Creating a positive, friendly, cooperative environment, the category of Tone of interactions groups similar indicators. 
Teachers identified indicators of rapport that we had not noted in the literature. We grouped one set of these indicators in the category Non text-based interactions. Some are specific to DE such as Setting up profiles or homepages. Other indicators referred to the use of specific tools such as chat, course café, email, video, webcam, and telephone. Teachers also provided more specific indicators than those we identified in the literature. For that reason, we included categories and subcategories as well as indicators. We might have referred to our subcategories as indicators and to our indicators as examples.

\section{Conclusion}

The findings presented in this paper are limited to teachers' beliefs. Beliefs of students enrolled in DE would not only have provided some triangulation but, as well, further insights into how important rapport, or some elements of it, might be in DE. The findings should also be interpreted in a context of virtual schooling (i.e., a high-school as opposed to a postsecondary context). An adolescent's needs for rapport might be different from those of postsecondary adults learning online. The scope of our questions limited the types of responses. A follow-up study using a more fine-grained focus on specific indicators might provide insights into specific rapport-related behaviours. The objective of the study was not to identify the types of rapport-building behaviours in which teachers are presently engaging. That type of focus might be taken in a follow-up study using interviews and online observations. Likewise, follow-up studies could explore the role of other factors that might influence either negatively or positively rapport-building in DE. These might include, for example, culture and language.

In spite of the limitations, this study highlights an element of DE about which little has been written. It provides indicators of rapport that might be used by DE teachers in their own teaching. The indicators might also be used in contexts of DE teacher professional development as a springboard for discussion or, more prescriptively, as guides to online teacher behaviour. They might be presented to teachers in survey format. Alternatively, the indicators might be used to measure rapport in the transcripts of online discussions or email correspondence. Finally, in terms of research, our study raises questions such as the following: Which indicators of rapport are most important in DE? What are the obstacles to building rapport in DE?

\section{Acknowledgements}

The study reported on in this paper was made possible by a grant from the Social Sciences and Humanities Research Council of Canada (SSHRC). Thank you to research assistants Kate Scarth, for her assistance with coding, Charlie O’Keefe and Janine Murphy, for recruitment of research participants, and Ying Zhang, for help with locating literature on rapport and with the reference list. 


\section{References}

Altman, I. (1990). Conceptualizing "rapport.” Psychological Inquiry, 1(4), 294-323.

Aviv, R. (2001). Educational performance of ALN via content analysis. Journal of Asynchronous Learning Networks, 4(2), 53-72. Retrieved from http://www.aln.org/ publications/jaln/v4n2/pdf/v4n2 aviv.pdf

Barnett, P. B. (2001). Rapport and the hospitalist. American Journal of Medicine, 111(9), 31-35.

Benson, T. A., Cohen, A. L., \& Buskist, W. (2005). Rapport: Its relation to student attitudes and behaviors toward teachers and classes. Teaching of Psychology, 32, 236-238.

Bernieri, F. J. (1988). Coordinated movement and rapport in teacher student interaction. Journal of Nonverbal Behavior, 12(2), 120-138.

Bernieri, F. J., Gillis, J. S., Davis, J. M., \& Grahe, J. E. (1996). Dyad rapport and the accuracy of its judgment across situations: A lens model analysis. Journal of Personality and Social Psychology, 71(1), 110-129. doi: 10.1037/0022-3514.71.1.110

Carey, J. C., Hamilton, D. L., \& Shanklin, G. (1986). Development of an instrument to measure rapport between college teachers. Journal of College Student Personnel, 27(3), 269-273.

Delaney, J., Johnson, A., Johnson. T., \& Treslan, D. (2010). Students' Perceptions of Effective Teaching in Higher Education. Retrieved from http://www.uwex.edu/disted/ conference/Resource library/handouts/28251 10H.pdf

DeWitt, T., \& Brady, M. K. (2003). Rethinking service recovery strategies: The effect of rapport on consumer responses to service failure. Journal of Service Research, 6(2), 193-207.

DeWitt, T., \& Liu, Y. (2002). The customer orientation-loyalty model: The role of emotional contagion and rapport in the service encounter. In W. J. Kehoe \& J. H. Lindgren Jr. (Eds.), 2002 American Marketing Association Summer Educators' Conference proceedings: Enhancing knowledge development in marketing (p. 321). Chicago, IL: American Marketing Association.

Fox, D. (1983). Personal theories of teaching. Studies in Higher Education, 8(2), 151-163.

Frisby, B. N., \& Martin, M. M. (2010). Instructor-student and student-student rapport in the classroom. Communication Education, 59(2), 146-164. doi:10.1080/03634520903564362

Gaglio, B., Nelson, C. C., \& King, D. (2006). The role of rapport: Lessons learned from conducting research in a primary care setting. Qualitative Health Research, 16(5), 
723-734.

Gillis, J., Bernieri, F. \& Wooten, E. (1995). The effects of stimulus medium and feedback on the judgment of rapport. Organizational Behavior and Human Decision Processes, 63, 33-46.

Granitz, N. A., Koernig, S. K., \& Harich, K. R. (2009). Now it's personal: Antecedents and outcomes of rapport between Business faculty and their students. Journal of Marketing Education, 31(1), 52-65. doi: 10.1177/0273475308326408

Gremler, D. D., \& Gwinner, K. P. (2000). Customer-employee rapport in services relationships. Journal of Services Research, 3(1), 82-104.

Hall, J. A., Roter, D. L., Blanch, D. C., \& Frankel, R. M. (2009). Observer-rated rapport in interactions between medical students and standardized patients. Patient Education and Counseling, 76(3), 323-327. doi: 10.1016/j.pec.2009.05.009

Jones, J., Warren, S., \& Robertson, M. (2009). Increasing student discourse to support rapport building in web and blended courses using a $3 \mathrm{~d}$ online learning environment. Journal of Interactive Learning Research, 2O(3), 269-294.

King, N., \& Horrocks, C. (2010). Interviews in qualitative research. London: Sage.

Kyriacou, C. (2009). Effective teaching in schools: Theory and practice ( $3^{\text {rd }}$ ed.). London: Nelson Thornes Publishers.

Lakin, J. L., \& Chartrand, T. L. (2003). Using nonconscious behavioural mimicry to create affiliation and rapport. Psychological Science, 14(4), 334-339.

Lee, R. M., \& Fielding, N. G. (2004). Tools for qualitative data analysis. In M. A. Hardy \& A. Bryman (Eds.), Handbook of data analysis (pp. 529-546). London: Sage.

Macintosh, G. (2009a). Examining the antecedents of trust and rapport in services: Discovering new interrelationships. Journal of Retailing and Consumer Services, 16(4), 298-305. doi:10.1016/j.jretconser.2009.02.001

Macintosh,G.(2009b).Theroleofrapportinprofessionalservices:Antecedentsandoutcomes. Journal of Services Marketing, 23(2), 71-79. doi:10.1108/08876040910946332

Marks, R. B. (1994), Personal selling: An interactive approach. Boston, MA: Allyn \& Bacon.

Marshall, J. (1981). Making sense as a personal process. In P. Reason \& J. Rowan (Eds.), Human inquiry: A sourcebook of new paradigm research (pp. 395-399). Chichester: John Wiley \& Sons.

Merriam, S. B. (2009). Qualitative research: A guide to design and implementation. San 
Francisco, CA: Jossey-Bass.

Miles, M. \& Huberman, A. M. (1994). Qualitative data analysis: An expanded sourcebook. Thousand Oaks, CA: Sage.

Miles, L. K., Nind, L. K., \& Macrae, C. N. (2009). The rhythm of rapport: Interpersonal synchrony and social perception. Journal of Experimental Social Psychology, 45(3), 585-589. doi:10.1016/j.jesp.2009.02.002

Murphy, E., \& Rodríguez-Manzanares, M. A. (2008a). Contradictions between the virtual and physical high-school classroom: A third-generation Activity Theory perspective. British Journal of Educational Technology, 39(6), 1061-1072. doi: 10.1111/j.1467-8535.2007.00776.x

Murphy, E., \& Rodríguez-Manzanares, M. (2008b). Revisiting Transactional Distance Theory in a context of web-based high-school distance education. Journal of Distance Education, 22(2), 1-14. Retrieved from http://www.sfu.ca/ ada27/JDE/MarkPDFs/Volo5/Murphy.pdf

Nickels, W. G., Everett, R. F., \& Klein, R. (1983). Rapport-building for salespeople: A neurolinguistic approach. Journal of Personal Selling and Sales Management, 3(2), 1-7.

Patton, M. Q. (2002). Qualitative research and evaluation methods ( $3^{\text {rd }}$ ed.). Thousand Oaks, CA: Sage.

Shapiro, S. (1989). Building proper rapport enhances guest relations. Restaurants and Institutions, 99, 22.

Siedentop, D. (1991). The mountain yet to be climbed. Paper presented at 1991 AIESEP NAPEHE World Congress, Atlanta.

Spencer-Oatey, H. (2000). Culturally speaking: Managing rapport through talk across cultures. London: Continuum.

Stock, M. (2010). The three R's: Rapport, relationship, and reference. The Reference Librarian, 51, 45-52. doi:10.1080/02763870903361995

Tickle-Degnan, L., \& Rosenthal, R. (1990). The nature of rapport and its nonverbal correlates. Psychological Inquiry, 1(4), 285-293.

\section{Athabasca University $\mathbf{A}$}

